\title{
Correction to: Structural Performance of Biaxial Geogrid Reinforced Concrete Slab
}

\author{
K. RajeshKumar ${ }^{1,2} \cdot$ P. O. Awoyera ${ }^{3}$ (D) G. Shyamala ${ }^{2} \cdot$ Vinod Kumar $^{4} \cdot$ N. Gurumoorthy ${ }^{5} \cdot$ \\ S. Kayikci ${ }^{6}$ L. M. Bendezú Romero ${ }^{7}$ A. Krishna Prakash ${ }^{8}$
}

Published online: 20 October 2021

(C) Iran University of Science and Technology 2021

\section{Correction to: International Journal of Civil Engineering https://doi.org/10.1007/s40999-021-00668-y}

In this article the second affiliation of the co-author's K. RajeshKumar and G. Shyamala was incorrectly given as Centre for Construction Methods and Materials, S R Engineering College, Warangal, Telangana, India It should have been

SR University, Warangal, Telangana, India
And In this article the affiliation of the co-author "A. Krishna Prakash was incorrectly given as

Department of Civil Engineering, PSNA College of Engineering and Technology, Dindigul, Tamil Nadu, India It should have been

Department of Civil Engineering, Anna University, Chennai

The original article has been corrected.

The original article can be found online at https:// doi.org/10.1007/s40999-021-00668-y.

P. O. Awoyera

paul.awoyera@covenantuniversity.edu.ng

K. RajeshKumar

k.rajeshkumar@sru.edu.in

G. Shyamala

S.murthy@sru.edu.in

Vinod Kumar

m.vinodkumar.civil@sr.ac.in

N. Gurumoorthy

guru.moorthy@sr.ac.in

S. Kayikci

safak.kayikci@ibu.edu.tr

L. M. Bendezú Romero ibendezur@uni.pe

A. Krishna Prakash

krishnaprakash3191@gmail.com
Centre for Construction Methods and Materials, S R Engineering College, Warangal, Telangana, India

2 SR University, Warangal, Telangana, India

3 Department of Civil Engineering, Covenant University, Ota, Nigeria

4 Department of Civil Engineering, Vel Tech High Tech Dr. Rangarajan Dr. Sakunthala Engineering College, Chennai 600 062, India

5 Department of Civil Engineering, PSNA College of Engineering and Technology, Dindigul, Tamil Nadu, India

6 Department of Computer Engineering, Bolu AbantIzzet Baysal University, Bolu, Turkey

7 Universidad Ricardo Palma, Lima, Peru

8 Department of Civil Engineering, Anna University, Chennai, India 